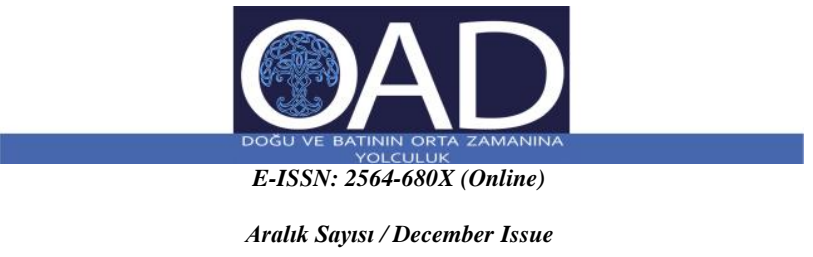

Yıl 3, Sayı 2 / Year 3, Issue 2

ATIF BILGISI / REFERENCE INFORMATION

ÖZER, Berkay Yekta, “II. Ioannes Komnenos Dönemi Bizans-Macar İlişkileri ve Sırp İsyanı (1127-1129)”, Ortaçă̆ Araştırmaları Dergisi, III/II, Aralık 2020, s. 435-441.

Makale Türü: Tarih Araştırma

DOI No: https://doi.org/10.48120/oad.826399

Geliş Tarihi / Received: 15 Kasım 2020 Online Yayın: 26 Aralı 2020
Kabul Tarihi / Accepted: 18 Aralı 2020

Published Online: 26 December 2020

\title{
II. Ioannes Komnenos Dönemi Bizans-Macar İlişkileri ve Sırp İsyanı (1127-1129) Berkay Yekta ÖZER ${ }^{1_{+}+}$
}

${ }^{1}$ Arş. Gör., Fırat Üniversitesi Insani ve Sosyal Bilimler Fakültesi, Tarih Bölümü, ELAZIĞ.

*byozer@firat.edu.tr

+ORCID: 0000-0003-1203-3531

$\ddot{\boldsymbol{O}} \boldsymbol{z}$ - Balkan toprakları Bizans İmparatorluğu açısından her daim önemli olmuştur. Gerek başkente açılan bir kapı olma özelliğine haiz olması gerekse de iktisadî ve stratejik potansiyeller barındırması bunda pay sahibidir. İmparatorluk bu topraklar üzerinde yaşanan siyasî gelişmeleri yakından takip etmiş ve her daim kontrol altında tutmak istemiştir. Ancak bazı dönemler kontrol mekanizmasını yitirmiştir. XI. yüzyıl krizi buna güzel bir örnek teşkil etmektedir. Mevzubahis zaman zarfında sarsılan otoritenin yeniden inşası anlamında Komnenosların payı oldukça büyüktür. Şüphesiz bu sürece en çok katkı veren imparatorların başında ise II. Ioannes Komnenos (1118-1143) gelmektedir. Uyguladığ1 etkili politika sayesinde Balkanlar'daki Peçenek tehdidi yok edilmiş, Sırplar, Bulgarlar ve Macarlar ise kontrol altına alınmıştır. Makalemizde Ioannes Komnenos'un Macarlar ekseninde yürüttüğü Balkan politikasına yer verilmiştir. Bu doğrultuda 1127-1129 yılları arasında gerçekleşen Bizans-Macar savaşları ile eş zamanlı ortaya çıkan Sırp ayaklanması ele alınmıştır.

Anahtar Kelimeler-Ioannes Komnenos, Balkanlar, Bizans, Macarlar, Sirplar.

\section{Byzantine-Hungarian Relations and the Serbian Revolt in the Era of John II. Komnenos}

\begin{abstract}
The Balkan lands have always been important to the Byzantine Empire. Both its being a gateway to the capital and having economic and strategic potentials play a role in this. The empire followed the policy that revolved on these lands closely and wanted to keep it under control at all times. However, some periods have lost the control mechanism. The crisis of the 11th century is a good example of this. The Komnenos dynasty share in terms of rebuilding the authority that was shaken during the time at issue is quite large. Undoubtedly, among the emperors who contributed the most to this process, John II Komnenos (1118-1143) is leading. Thanks to the effective policy it implemented, the Pecheneg threat in the Balkans was eliminated; Serbs, Bulgarians and Hungarians were taken under control. In our article, the Balkan policy carried out by John II Komnenos on the axis of Hungarians is included. In this direction, the Serbian uprising that occurred simultaneously with the Byzantine-Hungarian wars between 1127-1129 was also discussed.
\end{abstract}

Keywords - Ioannes Komnenos, Balkans, Byzantium, Hungarians, Serbs. 


\section{Giriş}

Makedon Hanedanı döneminin parlak geçen yıllarının ardından VIII. Konstantinos (1025-1028) ile birlikte "zaylf imparatorlar devri" başlamıştı. İmparatorluk XI. yüzyılın ortalarından itibaren siyasî, sosyal ve iktisadî anlamda büyük değişimlerin ve bozulmaların yaşandığı bir evreye girmişti. Bu sürecin Balkanlar'a yansıması sonucunda bölgenin siyasî aktörleri Bizans'in düştüğü durumdan faydalanmak adına yollar aramışlardı. Nitekim 1071 yılı bozgunundan sonra Balkan topraklarındaki Bizans nüfuzu azalmaya başlamış ve imparatorluk çok odaklı güçlere karşı zor durumda kalmıştı. Peçenekler bu duruma verilebilecek en güzel örneği teşkil ediyordu. Bulgarlar ise II. Basileios (976-1025) karşısında aldıkları yenilginin izlerini taşıyorlard. Bu nedenle mevzubahis siyasetten mahrumdular. Aslında X. yüzyılın ilk yarısına Bulgarlar damga vurmuştu. I. Simeon (893-927) öncülüğünde kurdukları Slav birliğ ile İstanbul önlerine kadar gelmişlerdi. Hâl böyle olunca imparatorluk çeşitli tavizler vermek zorunda kalmıştı. Yükselen Bulgar tehdidine karş1 II. Basileios'un Temmuz 1014'te aldığı büyük galibiyetle birlikte Bulgarlar Balkan siyasetinde devre dışı bırakılmıştı. ${ }^{1}$ Öyle ki II. Bulgar Krallığ1 (1185-1396) kurulana dek birkaç ayaklanma dışında sessizliklerini koruyacaktılar. Dolayısıyla II. Ioannes Komnenos'un Balkan politikasında Bulgarların rolü yoktu.

XI. yüzyılın başlarında, Bulgaristan'ın ilhakı ile Peçeneklere komşu olan imparatorluk bunun bedelini ağır ödemek zorunda kaldı. Nitekim askerî anlamda vermiş olduğu uzun soluklu mücadelelerden yenik ayrılmış ve Peçeneklerle masaya oturmuştu. Hâl böyle olunca Balkanlar'daki kadim sınırı Tuna'dan taviz vererek Balkan Dağları'nın ardına çekilmişti. Aleksios Komnenos (1081-1118) döneminde ise nüfuzları artan Peçenekler İstanbul önlerinde görünmeye başladılar. Norman tehdidini bertaraf eden imparator, diplomatik hünerleriyle Kumanları kullanarak 29 Nisan 1091'de Peçeneklere büyük bir darbe vurdu ve Balkanlar'daki sükûneti sağladı. ${ }^{2}$ Son olarak II. Ioannes Komnenos'un 1122'de aldığ galibiyetle birlikte Peçenekler imparatorluk için tehdit olmaktan çıktı. Bu hadise öylesine değerliydi ki zafer günü Peçenek Bayramı olarak kutlanacak ve tarih sayfalarında yer edinecekti. ${ }^{3}$ Geriye kalan Peçenek kitlelerinden bazıları ise Bizans'ın askerî stratejileri doğrultusunda değerlendirilen bir unsur olarak Balkan coğrafyasında kalmaya devam edeceklerdi.

Balkanlar'da dönen siyasetin önemli aktörlerinden biri de Sirplardı. Aslında X. yüzyılda Bizans hâkimiyetine karşı herhangi bir tehdit oluşturacak durumda değillerdi. Duklja, Raška, Travunija, Zahumlje, Pagania başta olmak üzere çeşitli Jupanlıklara ayrılmışlardı. Dolayısıyla siyasî birliktelikten mahrumdular. Sırbistan Theması adı altında imparatorluk idaresinde idiler. ${ }^{4}$ 1038-1039 yılında Sirp lider Stefan Vojislav önderliğinde bağımsızlıklarını kazandılar. Duklja hükümdarı Vojislav, diğer Jupanlıkları hâkimiyeti altına alarak İşkodra (Skadar) merkez olmak üzere Sırp Prensliğini kurdu. Bölgedeki gücü ve itibarı gittikçe artan Sırplar, Vojislav'ın ölümünden sonra (muhtemelen 1043) bir süre istikrarsız yapıya büründüler. Nitekim Stefan Vojislav'ın beş oğlu arasında paylaşılan topraklarda çeşitli ihtilaflar baş gösterdi. ${ }^{5} 1046$ senesinde tahta çıkan ve 35 y1l boyunca hüküm süren Mikhael (1046-1081) bu kargaşaya son vererek Sırp Prensliği’nin bağımsızlığını korudu. Söz konusu boşluktan yararlanmak isteyen İmparator IX. Konstantinos Monomakhos'un (1042-1055) çabaları sonucunda Dyrrhakhion (Draç) toprakları Bizans'a geçti. Mikhael için en önemli tehdit Bizans idi. Dolayısıyla koruduğu bağımsız yapının devamını sağlamak adına imparatorlukla bir barış antlaşması imzaladı. IX. Konstantinos Monomakhos ile bağ kurmak adına bir Bizans soylusu kadınla evlendi. Bizans kaynaklarının sessiz kaldığı bu evlilik sonucunda Protostrator unvanını elde etti. ${ }^{6}$ Gerçekleşen yakınlaşmalar Sırp tarafında herhangi bir statü kaybına yol açmadı. Ancak Bizans'ın Dyrrhakhion ve çevresi üzerindeki egemenliğini tanımak zorunda kaldilar.

Komnenoslar döneminde ise Sirplar tarih sahnesinde etkin roller almaya başladılar. Aleksios Komnenos döneminde kurulan ittifak ile başlayan Bizans-Sırp yakınlaşması Normanların Dyrrhakhion saldırısı ile birlikte farklı bir boyut kazandı. Nitekim Normanlara karşı imparatorluğun yanında yer alması gereken Konstantinos Bodin (1081-1101) tarafsiz kalarak Bizans'1n Dyrrhakhion'u kaybetmesinde etkin bir rol oynadı. $\mathrm{Bu}$ durumun oluşmasında Normanlarla kurmuş olduğu diplomatik ilişkinin etkisi vardı. ${ }^{7}$ Nitekim bu süreçte bölgedeki güçlü Bizans varlığını kendilerine büyük bir tehdit olarak gören Sırp yönetimi, imparatorluğa karşı farklı güç odaklarını kullanmaktan yana bir politika takip etmişti. Anna Komnena ise Konstantinos Bodin'in savaşın seyrine göre hareket ettiğini, Bizans aleyhine yaşanan gelișmelerin ardından muharebeye dâhil olmaktan kaçındığını belirtmiştir. ${ }^{8}$ Sonuç olarak Bodin'e güvenilmemesi gerektiğini tecrübe eden Aleksios Komnenos Sirplara karşı harekete geçerek Bodin'i mağlup ve esir etti. ${ }^{9}$ Duklja bu süreçten sonra önemini yitirerek bayrağ 1 Raška'ya devretti ki bu șehir Ortaçağ boyunca devlet merkezi olma potansiyeline sahip olacaktı. ${ }^{10}$

Bu süreçte Balkanlar'da Sırpların yaşadığı bölgeler Raška, Duklja, Zahumlje, Trebinje ve Bosna'nın bir kısmı idi. Dolayısıyla Bizans Sırplara karşı farklı mekânlarda mücadele vermek durumunda idi. Bunlardan en önemlileri; Dyrrhakhion ve Dubrovnik bölgelerinde hüküm süren Vojislavljević hanedanı ile Kosova ve İbar Vadileri boyunca yer tutan Vukanović hanedanı idi. ${ }^{11}$

Peçeneklerin ve Çaka Bey'in yol açtığı sorunların üstesinden gelen Aleksios Komnenos etkisini giderek arttıran Raška ile ilgilendi. Dyrrhakhion valisi yönetimindeki Bizans ordusunu 1092'de mağlup eden Sırplara karşı, 1093'te Raška üzerine yürüyen imparator, Büyük Jupan Vukan'ın (1092-1112) barış teklifi yapması üzerine geri döndü. Vukan, imparatorun bölgeden çekilmesiyle Vardar topraklarına doğru genişleme içerisine dâhil oldu ve Vranje, Skopje (Üsküp), Tetovo (Kalkandelen) şehirlerini aldı. Bunun üzerine 1094-1095'te sefere çıkan imparator bir barış teklifi ile daha karşılaştı. Zira Vukan,
${ }^{1}$ Ioannes Skylitzes, Synopsis Historiarum, nşr. I. Thurn, CSHB, V, Bonn, 1973, s. 475; John Skylitzes, A Synopsis of Byzantine History, 811-1057, İng. trc. Jean-Claude Cheynet, Bernard Flusin, and John Wortley, Cambridge University Press, Cambridge, 2010, s. 348-349; Ioannes Zonaras, Ioannis Zonarae epitome historiarum, nșr. L. Dindorf, III, Leipzig, 1870, s. 121-122 Tarihlerin Özeti, Trk. trc. Bilge Umar, Arkeoloji ve Sanat Yay., 2000, s. 4243.

2 Anna Komnena, Annae Comnenae Alexiadis, nşr. Ludovicus Schopenus, CSHB, Bonn, 1839, s. 401-410; Anna Comnena, The Alexiad, İng. trc Elizabeth A. S. Dawes, In parentheses Puplications Byzantine Series, Cambridge, 2000, s. 144-147; Anna Komnena, Alexiad: Malazgirt'in Sonrast, Trk. trc. Bilge Umar, İnk1lâp Kitabevi, İstanbul, 1996, s. 252-257.

${ }^{3}$ Niketas Khoniates, Nicetae Choniatae Historia, nşr. Immanuelis Bekkeri, CSHB, Bonn, 1835, s. 23; İng. trc. Harry J. Magoulias, Wayne State University Press, Detroit, 1984, s. 11; Trk. trc. Fikret Işıltan, TTK, Ankara, 1995, s. 11.
${ }^{4}$ Sima M. Circovic, The Serbs, İng. trc. Vuk Tosic, Blackwell Publishing, Malden, 2004, s. 21-22; Törebey Günaydın, Bizans ve Balkanlar (976-1076), Post Yayinevi, İstanbul, 2020, s. 57.

${ }^{5}$ John V. A. Fine, The Early Medieval Balkans: A Critical Survey from the Sixth to the Late Tvvelfth Century, The University of Michigan Press, 1991, s. 211-213; Paul Stephenson, Byznatium's Balkan Frontier, A Political Study of the Northern Balkans, 900-1204, Cambridge University Press, 2002, s. 138140.

${ }^{6}$ Ioannes Skylitzes, Thurn, s. 475; İng. trc., s. 442

7 John V. A. Fine, The Early Medieval Balkans, s. 222; Paul Stephenson, Byznatium's Balkan Frontier, s. 146-147.

${ }^{8}$ Anna Komnena, Schopenus, s. 214; İng. trc., s. 79; Trk. trc., s. 146.

${ }^{9}$ Anna Komnena, Schopenus, s. 367-368; İng. trc., s. 132; Trk. trc., s. 234.

${ }^{10}$ John V. A. Fine, The Early Medieval Balkans, s. 225.

${ }^{11}$ Sima M. Circovic, The Serbs, s. 29. 
Bizans birlikleri ile baş edemeyeceğini anlayınca kendi oğlu Uroš’u rehin vererek antlaşma çağrısında bulundu ve bu yolla imparatorluğun yüksek hâkimiyetini tanıdı. Kısacası Bizans'a karşı varlıklarını korumak adına çaba sarf eden Sırplar, Balkan topraklarındaki etkilerini arttırmak adına farklı siyasî oluşumlara destek vermeye her daim hazırdılar. Bu durum II. Ioannes Komnenos dönemine de yansıyacak ve Bizans-Macar savaşı (1127-1129) sırasında Macarların yanında yer alacaklardı.

Balkanlar'ın stratejik ve iktisadî potansiyeli Macarların daima ilgisini çekmişti. Öyle ki bu durum XI. ve XII. yüzyıllarda daha da önem kazanmıştı. Nitekim I. István (1000-1038) döneminden başlamak üzere doğu eksenli büyüme yolunda stratejiler gütmüşler ve gözlerini Adriyatik kıyılarına dikmişlerdi. ${ }^{12} \mathrm{Bu}$ süreçte bağımsızlıkların korumak adına Kutsal Roma Germen İmparatorluğu'na karş1 mücadele veren Macarlar, 1030 ve 1052'deki Alman akınların başarıyla savuşturmuşlardı. ${ }^{13}$ Ardından büyüyen Peçenek tehdidini önlemişler ve bölgedeki kontrol mekanizmalarını güçlendirmişlerdi. Macarlar XI. yüzyılda Kutsal Roma Germen tehlikesi altında olduklarından dış politikada etkin olamamışlardı. Ancak yine de Hırvatistan ve Dalmaçya sahilleri üzerine birtakım yayılmacı faaliyetler yürütmüşlerdi. Bu ise onları Bizans İmparatorluğu ile karşı karşıya getirecekti.

İlk olarak 934 yılı ile başlayan Macar akınları X. yüzyılda belli aralıklarla devam etmişti. ${ }^{14}$ XI. yüzyılın başlarında ise Bizans-Macar ilişkileri iyi bir seyirdeydi. Nitekim I. István, Bulgar-Bizans savaşları sürecinde II. Basileios'un yanında yer almıș ve 1018 yılında Bulgarlara karşı Bizans safında mücadele etmişti. ${ }^{15}$ Fakat Macarlar zaman zaman Balkanlar'ın iç kısımlarına doğru gerçekleştirdikleri yağma akınlarını da sürdürmüşlerdi. Örneğin Kral I. Endre döneminde Peçeneklerin de katılımıyla imparatorluğa karşı ortak bir askerî harekât düzenlenmiş ve bu girişim Isaakios Komnenos'un çabaları ile önlenebilmişti.

Taraflar arasındaki ilişkilerin önem arz etmeye başladığı yıllar ise XI yüzyılın son çeyreğinden itibaren başladı. Malazgirt bozgunu, Bari'nin kaybı, Norman tehdidi, Türklerin Anadolu'daki faaliyetleri ve Balkanlar'daki Peçenek, Kuman, Uz istilaları Bizans-Macar ilişkisinin boyutlarında büyüme meydana getirdi. Kral Salamon (1063-1074) ve Dük Géza'nın 1071 yılında düzenledikleri sefer sırasında Belgrad şehrini ele geçirmeleri oldukça önemli bir gelişmeydi. ${ }^{16} \mathrm{Bu}$ noktada imparatorluğun usta diplomasisi devreye girdi ve VII. Mikhael (1071-1078), Salamon ile Géza arasındaki hassas birlikteliği kullanarak taraflar arasındaki bağı kopardı. Bu sayede tehlike büyümeden durdu. Macarlar, Aziz László döneminde (1077-1095) Hirvatistan üzerinde egemenlik kurmak yolunda ciddi adımlar attılar. Dalmaçya kıyılarını hedef hâline getirdiler; fakat Kumanların Doğu Macaristan topraklarına saldırıları (1091) sonucunda bu plandan vazgeçmek zorunda kaldılar. ${ }^{17}$ Kral Kálmán (1095-1116) döneminde ise Bizans ve Venedik'e karşı Dalmaçya sahilleri için başlayan mücadeleler ilişkileri gerginleştirdi. 10961097'de Hırvatistan üzerindeki hâkimiyetini sağlamlaştıran Kálmán, Aleksios Komnenos'un Normanlara karşı vermiş olduğu mücadelede ise Bizans tarafında yer aldı. Dolayısıyla Macarların bölgedeki denge

${ }^{12}$ Nora Berend, "Hungary in the Eleventh and Twelfth Centuries", $N C M H$, IV, CUP, Cambridge, 2008, s. 304.

${ }^{13}$ Pal Engel, The Realm of St. Stephen, s. 28.

14 Gyula Moravcsik, Byzantium and The Magyars, Adolf M. Hakkert Publisher, Amsterdam, 1970, s. 55-61; Dimitri Obolensky, The Byzantine Commonwealth Eastern Europe, 500-1453, Praeger Publishers, New York, 1971, s. 153-158; T. Antonopoulos, "Byzantium, the Magyar Raids and Their Consequences", Byzantinoslavica, 54, 1993, II, s. 254-267.

${ }^{15}$ Gyula Moravcsik, Byzantium and The Magyars, s. 62; Pal Engel, The Realm of St. Stephen, s. 28; Z. J. Kosztolnyik, Hungary under the Early Arpads, 890s to 1063, East European Monographs, New York, 2002, s. 33; Nora Berend, "Hungary in the Eleventh and Twelfth Centuries", s. 306.

${ }^{16}$ Nikephoros Bryennios, Hüle Historias, nșr. Augustus Meineke, CSHB, Bonn, 1836, s. 100; Nikephoros Bryennios, Tarihin Ö̈z̈, Trk. trc. Bilge Umar, Arkeoloji ve Sanat Yayınları, İstanbul, 2008, s. 116. siyasetini de etkili bir şekilde yürüttükleri görülüyordu. II. Stephan (1116-1131) döneminde Bohemya ve Galiçya üzerine yoğunlaşan Macarlar, istedikleri bașarıyı elde edemediler. Yine de 1124'te Dalmaçya ve çevresini hâkimiyetleri altına aldılar. Atılan bütün bu adımlar, Bizans ile ortak beklentilerin ve planların gün yüzüne çıkmasını sağladı ve ilişkileri gerginleştirdi. Bu durum savaşa doğru uzanan süreci başlattı.

\section{Bizans-Macar Savaşı (1127-1229): Öncesi ve Sonrası}

Aziz László (1077-1095) ile birlikte gelişen ve Kálmán döneminde devam eden Bizans-Macar ilişkileri Komnenoslar devrinde önemli bir dış politika meselesi hâline geldi. Nitekim I. Aleksios Komnenos özellikle Norman tehdidine karşı müttefik arayışı içerisinde idi. İmparator gerek Doğu'da gerekse de Batı'da verdiği mücadelelerle XI. yüzyıl krizinin yaralarını sarmak adına büyük bir çaba sarf ediyordu. $\mathrm{Bu}$ sürecin bir ayağı da Adriyatik kıyılarında yaşanmaktaydı. Normanların amansız yükselişi karşısında zor günler geçiren Bizans, çok odaklı bir siyaset ortamı oluşturmak zorunda kalmıştı. Üstüne I. Haçlı Seferi'nin (1096-1099) meydana getirdiği kargaşa da eklenince Balkanlar' daki politik ortamı kontrol altına alma ihtiyacı hissedecekti.

1097 yılında Macar Kralı Kálmán, Norman Kralı Roger'in kızıyla evlendi. Papalığın ön ayak olduğu bu yakınlaşma Bizans ve Venedik'e karşı geliştirilen stratejik bir hamle idi. Öte yandan Bizans, Norman tehdidine karşı Venedik'i kendi yanına çekmişti. Ortak beklentilerin olması bu birlikteliği efektif kılmıştı. Ancak Normanların Balkanlar'da yürüttüğü politika ile kendisine bir müttefik grubu yaratması imparatorluk için büyük sorunlar meydana getirebilirdi. Dolayısıyla Bizans 1097'de Normanların Macar hamlesine karşılık olarak Venedik Doge'u Vitale Michiel'i Hırvat ve Dalmaçya dükü ilan etti. İmparatorluk, bu hamleye tepki gösteren Macarları kendi yanına çekmek adına da önemli adımlar attı. Nitekim sabık Kral Aziz László'nun kızı Piroska (Irene) ile Aleksios Komnenos'un oğlu Ioannes Komnenos arasında 1108 yılında bir evlilik gerçekleştirildi. ${ }^{18} \mathrm{Bu}$ durum daha önce yine bir evlilik yoluyla kurulan Macar-Norman birlikteliğini bozmak adına oldukça önemli bir gelişmeydi. Elbette söz konusu birliktelik kâğıt üzerinde olduğu kadar güçlü değildi. Zira Adriyatik kıyıları üzerine ilgisi olan Macarların bazı istekleri Bizans'ın dış politikası ile çelişmekteydi.

Kálmán 1102 yılında Zara (Zadar), Trau (Trogir), Sebenico (Šibenik), Aspalathos (Split) gibi önemli Dalmaçya şehirlerini ele geçirdi. Bu gelişmenin ardından kendisini Macar, Hırvat ve Dalmaçya Kralı ilan etti. ${ }^{19}$ 1107'deki Norman-Bizans çatışması sırasında Aleksios Komnenos'a askerî anlamda destek verdi. ${ }^{20}$ Bizans'ın Macarları kendi safına çekmesinde mezkûr evliliğin büyük katkısı olmuştu. Dolayısıyla XII. yüzyılın hemen başında Normanlara karşı BizansVenedik-Macar ittifakı kurulmuş oldu. Fakat Venedik 1112 yılında Dalmaçya'nın Macarlardan geri alınması için Bizans'tan yardım talep etti. Bizans müttefikinin bu isteğini geçiştirme yolunu tercih etti. Nitekim I. Aleksios Komnenos Normanlara karşı Macarları kendi safında tutmaya devam etmek istiyordu. Ayrıca bölgedeki güç dengelerini de göz önünde bulundurmalıydı. Bizans'tan umduğu

17 Mevzubahis süreçte Bizans'ın Kumanları Macar topraklarına doğru yönlendirdiğine dair görüşler mevcuttur. Nitekim Macarların Adriyatik'teki faaliyetleri Bizans'1 rahatsız etmişti. Bkz. Ferenc Makk, The Arpads and The Comneni Political Relations between Hungary and Byzantium in the 12th Century, Akademiai Kiado, Budapest, 1989, s. 10.

${ }^{18}$ Attila Barany, "The Politics of Piroska's Marriage: Byzantium, Hungary and the Normans in The Early Twelfth Century", Piroska and the Pantokrator Dynastic Memory, eds. Marianne Sághy, Robert G. Ousterhout, Central European University Press, New York - Budapeșt, 2019, s. 64-66.

${ }^{19}$ Z. J. Kosztolnyik, The dynastic policy of the Arpads, Geza I to Emery (10741204), East European Monographs, 2006, s. 81.

${ }^{20}$ Gyula Moravcsik, Byzantium and The Magyars, s. 70; Ferenc Makk, The Arpads and The Comneni, s. 15. 
yardımı alamayan Venedik, Ağustos 1115 'te Dalmaçya topraklarına saldırdı. Bir yıl sonra tekrarladığı seferlerle bölgedeki Macar egemenliğini sarstı. Venedik'in bu faaliyetlerine I. Aleksios Komnenos ile Kutsal Roma Germen İmparatoru V. Heinrick'in de destek verdiğine dair görüşler vardır. Ancak gerek Almanların İtalya Seferi (1116-1117) gerekse de Bizans'ın o sıralarda Selçuklular ve Ruslarla giriștiği mücadeleler Venedik'e somut anlamda bir desteğin sağlanmasının zor olduğunu göstermektedir.

Macar-Venedik savaşları sırasında Bizans'ın Venedik lehine bir tavır takınması Macarlar için kötü bir anı olmuştu. Ayrıca Venedik'in Dalmaçya'daki faaliyetleri Macarların etkisini kırmış; II. István'ın 1124'ün başlarında giriștiği harekât ise uzun süreçte bir başarı sağlamamıştı. Yaklaşık on y1l süren mücadelenin ardından 1125 'te Macarlar bir barıș antlașması imzalamak durumunda bırakılmıșt. ${ }^{21}$ Ancak Adriyatik üzerine şekillenen Bizans-Venedik-Macar ihtilaf devam edecek ve bütün bir yüzyıl boyunca sürecekti. Bahsi geçen tüm bu gelişmeler, Macarların Bizans'a karşı olan tutumlarını gittikçe sertleştirecek ve savaşa doğru uzanan süreci hızlandıracaktı.

Aleksios Komnenos'un yaklaşık otuz yedi yıl süren yönetimi zarfinda; Norman ve Peçenek tehdidi yok edilmiş, Haçlıların ortaya çıkardığ1 sorunlar çözülmüş ve Türklerin Batı Anadolu'daki ilerleyişleri durdurulmuştu. İmparatorun 1118'deki ölümünün ardından yerine oğlu II. Ioannes Komnenos (1118-1143) geçti. Babasının zorlu ve uzun geçen hükümdarlığ 1 ona rahat bir politik ortam oluşturdu. İlk iş olarak Venedik'e verilen ticarî imtiyazları (Chrysobull) gözden geçiren imparator bu defa Macarların Dalmaçya hâkimiyetini onaylama yönünde bir karar ald.$^{22}$ Öyle ki Venedik'in bölgede giderek güçlenmesi ekonomik ve siyasî anlamda yeterince kaygı yaratmıștı. Bu nedenle imparator, Venedik Doge'u Domenico Michiel'in 1082'de verilen imtiyazların yenilenmesi doğrultusundaki isteğini reddetti. Venedik, II. Ioannes'in bu kararına donanma gücüyle karşılık verdi. Kefalonya başta olmak üzere stratejik ada ve limanlar üzerinde baskı kurdu. ${ }^{23}$ Venediklilerin bu girişimleri nedeniyle imparator, Ağustos 1126 'da imtiyazları yenilemek durumunda kaldı. ${ }^{24}$ Adriyatik'teki güç dengeleri üzerine şekillendirdiği planlarının ilk ayağı başarısız olan imparator, Venedik'e karşı Macarları desteklemek üzere oluşturduğu politikasından da vazgeçmek durumunda kaldı.

Bizans-Macar savaș ${ }^{25}$ bütün bu süreçler etrafında şekillendi ve Macarların 1127'deki saldırılarıyla patlak verdi. ${ }^{26}$ Savaşın görünürde iki farklı nedeni vardı. Niketas Khoniates'e göre Macarların beklenmedik bir anda saldırmalarının nedeni II. István'ın amcası Álmos'un Bizans'a sığınması idi. ${ }^{27}$ Sabık Kral Kálmán, oğlu István'ın tahtını sağlama almak adına kardeşi Álmos ve onun oğlu Béla'yı kör ettirmişti. ${ }^{28}$ Bunun üzerine Álmos maiyetindekilerle birlikte İstanbul'a sığınmıştı. İmparator Álmos'u oldukça iyi karşılamış ve ona Makedonya topraklarında bir şehir tahsis etmişti. Bu yer kısa sürede Álmos destekçisi Macar sığınmacılarının merkezi olmuştu. ${ }^{29}$ Bunun üzerine Macar yönetimi uzun bir süre mezkûr sı̆̆ınmacıların teslim ve sınır dışı edilmesini talep etti. İmparator Ioannes'in bu istekleri geri çevirmesi aradaki ilişkileri gerginleştirdi. Nitekim Ioannes Kinnamos da savaşın nedeni olarak Álmos'un ilticasını işaret ederek II. István'ın taleplerine yer vermiştir. ${ }^{30}$ Dolayısıyla savaşın patlak vermesinde bu olay önemli biri paya sahiptir. Niketas ise Macar tarafının öne sürdügü nedene de yer vererek; Braničevo şehrinde Macar tüccarlarının maruz kaldığı şiddet ve soygunun onlara saldırmaları yönünde bir bahane yarattığını ve bunu ayıplarını örtmek amacıyla kullandıklarını belirtmiştir. ${ }^{31}$ Braničevo şehri, Macaristan'dan başlayarak Belgrad, Sofya ve Filibe'den İstanbul'a uzanan ticari yol ağı içerisinde oldukça önemli bir merkezdi. Dolayısıyla söz konusu şehir üzerine yaşanan gelişmeler birtakım ticari faktörler etrafında şekillenmişti. Yani taraflar arasında ortaya çıkan gerginliğin bir nedeni de ekonomik beklentilerdi. Ayrıca Ioannes Komnenos'un II. István'ı politik açıdan vasalı olarak değerlendirmesi Macar tarafında bir başka haklı neden olarak görülüyordu. ${ }^{32}$

Álmos'un iade edilmesi yönündeki talebi reddedilen II. István, ordusunu hazırlayarak 1127 yazında Bizans topraklarına saldırdı. Balkan içlerine doğru ilerleyen Macar ordusu Belgrad, Braničevo, Niş ve Sofya'yı yağmalad. ${ }^{33}$ Niketas'a göre ilk olarak Braničevo hedef alınmış, şehrin surları yıkılarak, taşları Zeugminon şehrine taşınmıştı. ${ }^{34}$ Kinnamos ise saldırının Belgrad ile başladığını belirtmiş ve surları yıkılan şehrin de Belgrad olduğunu vurgulamıştır. ${ }^{35} \mathrm{Bu}$ sirada Filibe'de bulunan II. Ioannes Komnenos ilerleyen Macar birliklerini durdurmayı başardı ve çekilmeye zorladı. Ardından karşı bir saldırı için hazırlıklara başlayan imparator, 1128 'de bizzat yönettiği ordu ile Macarlara karşı sefere çıktı. Hem kara hem de donanma güçleriyle gerçekleştirdiği bu harekâta Lombardlar ve Selçuklu birlikleri de destek verdi. ${ }^{36}$ Tuna hattını savunan Macar birlikleri Sirmion ve Temesköz civarında sıkıştırıldı. Bizans donanmasının Tuna'daki başarılı ilerleyiși ile birlikte Haram (Khramos) Kalesi önlerinde karşı karşıya gelen ordular Karas Nehri
${ }^{21}$ Donald M. Nicol, Bizans ve Venedik Diplomatik ve Kültürel Illişkiler Üzerine, Trk. trc. Gül Çağalı Güven, Sabancı Üniversitesi Yayınları, İstanbul, 2000, s. 71.

${ }^{22}$ Donald M. Nicol, Bizans ve Venedik, s. 75.

${ }^{23}$ W. Heyd, Yakın -Doğu Ticaret Tarihi, Trk. trc. Enver Ziya Karal, Ankara TTK, 1975, s. 212-213; Michael Angold, The Byzantine Empire 1025-1204; A Political History, New York, 1997, s. 186.

${ }^{24}$ Donald M. Nicol, Bizans ve Venedik, s. 76-77; Dafni Penna, The Byzantine Imperial Acts to Venice, Pisa and Genova 10th-12th Centuries, Eleven International Publishing, Groningen, 2012, s. 35-36.

${ }^{25}$ Bizans kaynaklarının herhangi bir zaman dilimi belirtmemesi, kronolojik anlamda birtakım anlaşmazlıklar ortaya çıkarmıștır. Bazı araștırmacılar ilk Macar saldırısını 1125 'e tarihlendirerek, mücadelelerin 1125-1126 yıllar arasında vuku bulduğunu iddia etmişlerdir. Sırp isyanını ise 1123'ün başlarına ve 1124 yılına tarihlendirenler mevcuttur. Biz makalemizde özellikle Gyula Moravcsik, Adrew B. Urbansky ve Ferenc Makk'ın kullandıkları kronolojiy baz aldık. Nitekim Bizans-Macar antlaşmasının tarihi konusunda bir Bohemya kaynağı sayesinde bilgi sahibiyiz. II. István'ın 1129 yılında Braničevo üzerine gerçekleștirdiği sefere Bohemya Prensi Vaclav da katılmıș ve döndükten dört ay sonra Şubat 1130 'da hayatını kaybetmişti. Dolayısıyla bu bilgi savaşın Ekim 1129 'da bittiğini doğrulamaktadır. Sırp ayaklanmasının ise bu süreç aralığında gerçekleştiği kabul edilmelidir. Bkz. Ferenc Makk, The Arpads and The Comneni, s. 27.

${ }^{26}$ Süreç hakkında bilgi veren iki önemli Bizans kaynağının mukayesesi için bkz. Paul Stephenson, "John Cinnamus, John II. Comnenus and the Hungarian
Campaign of 1127-1129”, Byzantion, 66, I, 1996, 177-187. Krş. Gyula Moravcsik, Byzantium and The Magyars, s. 78-79; Andrew B. Urbansky, Byzantium and the Danube Frontier, Twayne Publishers, New York, 1968, s. 45-47; Ferenc Makk, The Arpads and The Comneni, s. 22-30; John V. A. Fine, The Early Medieval Balkans, s. 234-236; Paul Stephenson, Byznatium's Balkan Frontier, s. 205-210; Alexandru Madgearu, Byzantine Military Organization on the Danube, 10th-12th Centuries, Brill, Leiden, 2013, s. 149150 .

${ }^{27}$ Niketas Khoniates, Bekkeri, s. 23; İng. trc., s. 11; Trk. trc., s. 11.

${ }^{28}$ Z. J. Kosztolnyik, The dynastic policy of the Arpads, s. 101.

29 Andrew B. Urbansky, Byzantium and the Danube Frontier, s. 40; Ferenc Makk, The Arpads and The Comneni, s. 22.

${ }^{30}$ Ioannes Kinnamos, Epitome, nşr. A. Meineke, CSHB, Bonn, 1836, s. 9; John Kinnamos, Deeds of John and Manuel Comnenus, İng. trc. Charles M. Brand, Columbia University Press, New York, 1976, s. 17; Ioannes Kinnamos, Ioannes Kinnamos 'un Historia 'sı (1118-1176), Trk. trc. Işın Demirkent, TTK, Ankara, 2001, s. 9.

${ }^{31}$ Niketas Khoniates, Bekkeri, s. 23; İng. trc., s. 11; Trk. trc., s. 11.

${ }^{32}$ Emericus Szentpetery, Scriptores Rerum Hungaricarum, Tempore Ducum Regumque Stirpis Arpadianae Gestarum, I, Budapeşte, 1937, s. 439-440.

${ }^{33}$ Gyula Moravcsik, Byzantium and The Magyars, s. 78; Ferenc Makk, The Arpads and The Comneni, s. 24.

${ }^{34}$ Niketas Khoniates, Bekkeri, s. 23; İng. trc., s. 11; Trk. trc., s. 11.

${ }^{35}$ Ioannes Kinnamos, Meineke, s. 10; Ing. trc., s. 18; Trk. trc., s. 10.

${ }^{36}$ Ioannes Kinnamos, Meineke, s. 10; İng. trc., s. 18; Trk. trc., s. 10 
civarında şiddetli bir savaşa tutuştu. ${ }^{37}$ Büyük bir zafer elde eden Ioannes Komnenos, Sirmion, Semlin şehirleri ile Haram Kalesi'ni ele geçirdi. Macar kroniği imparatorluk donanmasının Grek Ateşi'ni kullanarak Macar gemilerini yok ettiğini ve bu gelişmenin savaşın kaybedilmesinde büyük bir rol oynadığını kaydetmiştir. Ayrıca Haram Kalesi önlerinden yaşanan çarpışmanın oldukça sert geçtiğini betimlemek adına Karas Nehri'nin "insan kanıyla aşılandığını" yazmıştır. ${ }^{38}$

Ancak kalıcı bir işgal politikası gütmeyen imparator, Braničevo şehrini güçlendirdikten sonra İstanbul'a döndü. Ioannes'in bu zaferi Macar iç siyasetinde derin etkiler yarattı. Nitekim Bizans'a karşı askerî bir çatışmanın doğru olmadığını, bunun yanlış bir hamle olduğunu savunan muhalif görüşler ortaya çıtı. Bu süreçte II. István hasta idi. Bir kesim muhalif gruplar Bors ve Ivan'ı kral ilan ettiler. Ancak II. István iyileştikten sonra destekçileri ile birlikte taht adaylarından Ivan'ı ortadan kaldırdı. Bors ise Bizans'a sığınmak durumunda kaldı ve Álmos'un ardından ikinci önemli sığınmacı oldu. ${ }^{39}$ İktidarını yeniden pekiştiren II. István, 1129 'un ilk yarısında Bohemya ordusunun da desteğiyle tekrardan Braničevo'ya saldırdı. $\mathrm{Bu}$ harekâta eş zamanlı olarak Sırp isyanı patlak verdi. Bir sonraki başlıkta ele alacağımız bu isyanın ortaya çıkmasında Macar-Sırp yakınlaşması büyük rol oynadı. İlk önce Sırplar üzerine yürüyen imparator isyanı başarıyla bastırdı ve ardından Macar topraklarına girdi. Braničevo üzerindeki hâkimiyetini yeniden kuvvetlendiren Ioannes, kış şartlarının bastırması ve erzak yokluğu nedeniyle zor zamanlar geçirdi. Macar ordusunun saldırıları karşısında geri çekilmek zorunda kalan Bizans birlikleri bölgeden ayrıldı Muhtemelen Ekim 1129'da Bizans ve Macar elçileri Tuna Nehri üzerinde, Braničevo yakınlarındaki adada bir araya geldiler ve savaşa son noktayı koyacak antlaşmayı imzaladılar. ${ }^{40}$ İmparator Ioannes'in Kilikya politikası ile ilgilenmesi için uygun bir ortama ihtiyacı vardı. ${ }^{41}$ Öyle ki bu sıralarda Doğu odaklı bir dıș politika belirlemiști. $\mathrm{Bu}$ nedenle Macarlarla antlaşma yolunu tercih etti. Macar tarafinda ise Bizans ile uzayan mücadelelerden rahatsızlık duyan gruplar mevcuttu. Ayrıca savaşın başlamasına yol açan en büyük nedenlerden biri ortadan kalkmıştı. Zira Álmos 1 Eylül 1127'de hayatını kaybetmişti. Öte yandan Bizans'ın Macaristan'1 fethetmek gibi bir niyeti yoktu. ${ }^{42}$ İç dinamikleri buna elverecek ölçüde değildi. Dolayısıyla taraflar bölgedeki statükonun korunmasından yana bir tavır sergileyerek masaya oturmuşlardı. Sonuçta Ioannes Komnenos'un süreç içerisindeki askerî ve politik hamleleriyle Macarlar Doğu Balkanlar'dan uzaklaştırıldı; Braničevo, Belgrad ve Sirmion şehirleri kurtarıldı.

Ağustos 1135'de Bizans-Kutsal Roma Germen ve Venedik arasında Normanlara karşı bir ittifak oluşturuldu. Macarlar bu süreçten faydalanmak adına Dalmaçya kıyılarındaki hâkimiyetlerini sağlamlaştırdılar. Ancak söz konusu durum gerek Venedik gerekse de Bizans için büyük bir sorun teşkil etmedi. Nitekim Norman tehdidi en çok önem verdikleri mesele idi. Dolayısıyla ilișkilerde bozulma yaşanmadı. Ayrıca 1137'de Álmos'un naaşı Bizans topraklarından Macaristan'a götürüldü. Bu gelişme ise devletlerarasında bir gerginliğin olmadığını ișaret etmektedir. Fakat Ioannes Komnenos'un ardından tahta geçen I. Manuel (1143-1180) döneminde ilişkiler yeniden kopacak ve Tuna hattında mücadeleler yeniden baş gösterecekti.

${ }^{37}$ Emericus Szentpetery, Scriptores Rerum Hungaricarum, s. 441; Niketas Khoniates, Bekkeri, s. 24; İng. trc., s. 12; Trk. trc., s. 12; Ioannes Kinnamos, Meineke, s. 10; İng. trc., s. 18; Trk. trc., s. 10.

${ }^{38}$ Emericus Szentpetery, Scriptores Rerum Hungaricarum, s. 441-442.

${ }^{39}$ Ferenc Makk, The Arpads and The Comneni, s. 25.

${ }^{40}$ Emericus Szentpetery, Scriptores Rerum Hungaricarum, s. 442.

${ }^{41}$ Martin Marko Vucetic, "Emperor John II's encounters with foreign rulers",

John II Komnenos, Emperor of Byzantium: In the Shadow of Father and Son,

\section{Sırp Ayaklanması ve Sürece Etkileri}

Aleksios Komnenos döneminde hâkimiyet altına alınan Sırplar, bölgedeki Bizans gücünü kendi bağımsızlıkları adına en büyük tehlike olarak görüyorlardı. Bu anlamda imparatorluğa karşı bir müttefik bulma arayışında olmaları oldukça normaldi. Daha önceden Raška Jupanı Vukan'1 kontrol altına alan Aleksios, yukarıda bahsettiğimiz üzere belirli teminatlar karşılığında bir barıș antlaşması imzalamıştı. Fakat II. Ioannes Komnenos döneminde, Niketas'ın da belirttiği üzere Sırplar antlaşmaya uymayarak Bizans topraklarına saldırdılar. $\mathrm{Bu}$ saldırının zamanlaması ise oldukça manidardı. Nitekim Macar Kralı II. István'ın 1129'da Braničevo'ya saldırısıyla eş zamanlı gerçekleşmişti. ${ }^{43}$ Dolayısıyla taraflar arasında bir ittifak kurulduğu aşikârdı.

Raška Jupanı I. Uroš ile II. István'ın 1129 yılı öncesinde Bizans'a karşı bir antlaşma imzaladıkları anlaşılıyordu. Daha sonradan bu yakınlaşma bir evlilikle daha somut hâle getirildi. Zira 1130'da Uroš'un kızı Jelena ile II. István'ın kendisine vâris olarak tayin ettiği Béla arasında bir evlilik gerçekleşti. Çeyiz olarak Macarlar Kuzey Sırbistan'ı aldılar. ${ }^{44}$ II. István'ın ardından başa geçen II. Béla 1141 yılında ölecek ve tahtı Jelena'dan olma II. Géza devralacaktı. Böylece Macar-Sırp yakınlaşması XII. yüzyılın büyük bir bölümünde devam edecekti.

II. István'ın Braničevo'ya saldırısı sırasında Raška Jupanı I. Uroš, Bizans yönetimi altındaki Ras şehrini ele geçirdi ve büyük bir tahribata uğrattı. Sırp isyanı stratejik anlamda Belgrad, Nis ve Sofya yolunu Bizans açısından tehlikeli hâle getirdi. ${ }^{45} \mathrm{Bu}$ beklenilmedik gelişmeler karşısında harekete geçen II. Ioannes Komnenos ilk olarak Sırplar üzerine yürüdü. İmparator karşısında çaresiz kalan Sırplar yaptıklarının bedelini çok ağır bir şekilde ödemek durumunda kaldılar. Nitekim kısa sürede aldıkları mağlubiyetle maddi anlamda büyük bir kayba uğradılar. Ayrıca birçoğu Nikomedia (İzmit) ve çevresine çiftçi olarak yerleştirildi. Bazıları ise askerî ihtiyaçlar doğrultusunda orduya alındı. ${ }^{46}$ Raška Jupanlığ 1 ise tekrardan Bizans hâkimiyetini tanımak zorunda kaldı.

Macar-Sırp yakınlaşması Balkanlar'daki kontrolün sağlanması noktasında tehlikeli bir hâl alabilirdi. Nitekim stratejik anlamda önemli yol güzergâhlarını tutan Sırplar, Bizans kuvvetlerine zor anlar yaşatabilirdi. Ancak tüm bunlar İmparator Ioannes Komnenos'un süratli müdahalesiyle engellenmiş ve Macarların politik hamlesi boşa çıkarılmıştı.

\section{Sonuç}

“Imparatorluğun göz bebeği” olarak nitelendirilen Balkan toprakları sahip olduğu potansiyel ve stratejik önemi sayesinde bölgedeki siyasî aktörlerin ana hedefi konumundaydı. Barındırdı $\breve{g}_{1}$ etnik unsurlarla kozmopolit bir yapıda olan bu coğrafya, Bizans'ın iç dinamiklerini oluşturan belli başlı etmenlerden biriydi. Nitekim imparatorluk mezkûr toprakların savunulması konusuna daima önem vermiști. Bu doğrultuda gerek askerî gerekse de politik anlamda ortaya koyduğu mücadeleler ile yüzyıllar boyunca egemenliğini sürdürmüştü. Mevzubahis süreç içerisinde çeşitli güç odaklarıyla karşı karşıya gelen imparatorluk bazı dönemlerde yaşadığı düşüş ile Balkanlar'daki hâkimiyetini onarmak durumunda kalmıştı. Şüphesiz bu evrelerden en önemlisi ise Komnenos restorasyonuydu. I. Aleksios ile başlayan ve ardından II. Ioannes ile devam eden zaman zarfında
Eds. Alessandra Bucossi, Alex Rodriguez Suarez, Routledge, New York, 2016, s. 74,77,79-80.

${ }^{42}$ Ferenc Makk, The Arpads and The Comneni, s. 28

${ }^{43}$ Ioannes Kinnamos, Meineke, s. 12; İng. trc., s. 19; Trk. trc., s. 11.

${ }^{44}$ John V. A. Fine, The Early Medieval Balkans, s. 236

${ }^{45}$ Alexandru Madgearu, Byzantine Military Organization, s. 149.

${ }^{46}$ Niketas Khoniates, Bekkeri, s. 23; İng. trc., s. 11; Trk. trc., s. 11. 
Peçenek tehdidi yok edilmiş, Norman ilerleyişi durdurulmuş, Bulgarlar ise kontrol altında tutulmuştu.

II. Ioannes döneminde Bizans-Macar ilişkileri kritik bir mesele hâline geldi. Macarların XI. yüzyılın başlarından itibaren ortaya çıkan Dalmaçya kıyılarına olan ilgileri ve Doğu Balkanlar'ın iç kesimlerine doğru yaptıkları akınlar, Bizans diplomasisinde daha fazla yer almalarını sağladı. II. Ioannes Komnenos bu gelişmeler karşısında farklı diplomatik yollara başvurmayı tercih etti. Daha önceden Macar prensesi Piroska ile yaptıkları evlilik taraflar arasındaki ilişkileri iyi bir seviyeye çekmişti. Nitekim Norman tehdidine karşı Bizans-Macar ittifakı kurulmuş ve Bizans-Macar-Venedik ortaklığı sağlanmıştı. Ancak Venedik'in Adriyatik'teki çıkarları sonucu Macarlara saldırmaları bu birlikteliği kâğıt üzerinde bırakmıştı. Ardından II. Ioannes'in Doğu Akdeniz'de giderek güçlenen Venedik'e karş1 Macarları desteklemesi oldukça stratejik bir hamle idi. Fakat özellikle Álmos'un Bizans'a ilticası ve Braničevo'da Macar tüccarlarına yapılan saldırılar, Macarların Bizans'a olan bakış açılarını değiştirdi. Bunda II. István'ın uzun vadeli planları da etkili idi. Nitekim Bizans'ın bölgedeki iktidarından rahatsız olduğu ve çevredeki siyasî güçlerden Bizans'a karşı destek arayışına girdiği aşikârdı. Gerilen ilişkiler savaşa doğru giden süreci hızlandırdı ve 1127'de patlak veren Bizans-Macar savaşı Ekim 1129'da yapılan bir antlaşma ile sona erdi. II. Ioannes'in etkili hamleleri neticesinde Doğu Balkanlar'dan Macar tehlikesi uzaklaştırıldı ve bölgedeki statüko tekrar sağlandı. Süreç içerisinde ortaya çıkan bir diğer gelişme ise 1129'daki Sırp ayaklanması oldu. Raška Jupanı I. Uroš, II. István ile yaptığı ittifaka dayanarak, Macarların Braničevo'ya yaptıkları ikinci saldırıya eș zamanlı olarak Ras şehrini yağmaladılar ve Bizans yönetimine karșı isyan ettiler. Fakat imparatorun süratli hamlesi karşısında mağlup olan Sırplar isyanın bedelini çok ağır ödemek zorunda kaldılar.

Sonuç olarak ele aldığımız süreç içerisinde, ortaya koyduğu kararlı mücadele ile Balkanlar'da sarsilan Bizans nüfuzunu yeniden sağlamlaştıran II. Ioannes Komnenos, politik dünyasında ağırlık verdiği Doğu'ya odaklanmak için gerekli ortamı sağladı. 


\section{KAYNAKÇA}

Angold, Michael, The Byzantine Empire 1025-1204; A Political History, New York, 1997.

Anna Komnena, Annae Comnenae Alexiadis, nşr. Ludovicus Schopenus, Corpus Scriptorum Historiae Byzantinae, Bonn, 1839; Anna Comnena, The Alexiad, İng. trc. Elizabeth A. S. Dawes, In parentheses Puplications Byzantine Series, Cambridge, 2000; Anna Komnena, Alexiad: Malazgirt'in Sonrası, Trk. trc. Bilge Umar, İnkılâp Kitabevi, İstanbul, 1996.

Antonopoulos, T. "Byzantium, the Magyar Raids and Their Consequences”, Byzantinoslavica, 54, 1993, II, s. 254-267.

Barany, Attila, "The Politics of Piroska's Marriage: Byzantium, Hungary and the Normans in The Early Twelfth Century", Piroska and the Pantokrator Dynastic Memory, eds. Marianne Sághy, Robert G. Ousterhout, Central European University Press, New York - Budapeşt, 2019, s. 63-96.

Berend, Nora "Hungary in the Eleventh and Twelfth Centuries", NCMH, IV, CUP, Cambridge, 2008, s. 304-316.

Circovic, Sima M., The Serbs, İng. trc. Vuk Tosic, Blackwell Publishing, Malden, 2004.

Fine, John V. A. The Early Medieval Balkans: A Critical Survey from the Sixth to the Late Tvvelfth Century, The University of Michigan Press, 1991.

Günaydın, Törebey, Bizans ve Balkanlar (976-1076), Post Yayınevi, İstanbul, 2020.

Heyd, W., Yakın -Doğu Ticaret Tarihi, Trk. trc. Enver Ziya Karal, Ankara, TTK, 1975.

Ioannes Kinnamos, Epitome, nşr. A. Meineke, CSHB, Bonn, 1836,; John Kinnamos, Deeds of John and Manuel Comnenus, İng. trc. Charles M. Brand, Columbia University Press, New York, 1976; Ioannes Kinnamos, Ioannes Kinnamos'un Historia'sı (1118-1176), Trk. trc. Işın Demirkent, TTK, Ankara, 2001.

Ioannes Skylitzes, Synopsis Historiarum, nşr. I. Thurn, Corpus Scriptorum Historiae Byzantinae, V, Bonn, 1973; John Skylitzes, A Synopsis of Byzantine History, 811-1057, İng. trc. Jean-Claude Cheynet, Bernard Flusin, and John Wortley, Cambridge University Press, Cambridge, 2010.

Ioannes Zonaras, Ioannis Zonarae epitome historiarum, nşr. L. Dindorf, III, Leipzig, 1870; Tarihlerin Özeti, Trk. trc. Bilge Umar, Arkeoloji ve Sanat Yayınları, 2000.

Kosztolnyik, Z. J., Hungary under the Early Arpads, 890s to 1063, East European Monographs, New York, 2002.

, The dynastic policy of the Arpads, Géza I to Emery (1074-1204), East European Monographs, 2006.

Madgearu, Alexandru, Byzantine Military Organization on the Danube, 10th-12th Centuries, Brill, Leiden, 2013.

Makk, Ferenc The Arpads and The Comneni Political Relations between Hungary and Byzantium in the 12th Century, Akademiai Kiado, Budapest, 1989.

Moravcsik, Gyula, Byzantium and The Magyars, Adolf M. Hakkert Publisher, Amsterdam, 1970.

Nikephoros Bryennios, Hüle Historias, nşr. Augustus Meineke, CSHB, Bonn, 1836; Nikephoros Bryennios, Tarihin Özü, Trk. trc. Bilge Umar, Arkeoloji ve Sanat Yayınları, İstanbul, 2008.

Niketas Khonıates, Nicetae Choniatae Historia, nşr. Immanuelis Bekkeri, CSHB, Bonn, 1835; İng. trc. Harry J. Magoulias, Wayne State University Press, Detroit, 1984, s. 11; Trk. trc. Fikret Işıltan, TTK, Ankara, 1995.

Nicol, Donald M., Bizans ve Venedik Diplomatik ve Kültürel İlişkiler Üzerine, Trk. trc. Gül Çağalı Güven, Sabancı Üniversitesi Yayınları, İstanbul, 2000.

Obolensky, Dimitri The Byzantine Commonwealth Eastern Europe, 500-1453, Praeger Publishers, New York, 1971.

Penna, Dafni, The Byzantine Imperial Acts to Venice, Pisa and Genova 10th-12th Centuries, Eleven International Publishing, Groningen, 2012. Stephenson, Paul, Byznatium's Balkan Frontier, A Political Study of the Northern Balkans, 900-1204, Cambridge University Press, 2002. Szentpetery, Emericus, Scriptores Rerum Hungaricarum, Tempore Ducum Regumque Stirpis Arpadianae Gestarum, I, Budapeşte, 1937. Urbansky, Andrew B., Byzantium and the Danube Frontier, Twayne Publishers, New York, 1968.

Vucetic, Martin Marko “Emperor John II's encounters with foreign rulers”, John II Komnenos, Emperor of Byzantium: In the Shadow of Father and Son, Eds. Alessandra Bucossi, Alex Rodriguez Suarez, Routledge, New York, 2016, s. 71-90. 